\title{
Rancang Bangun Sistem Informasi Pembiayaan Kredit Mobil Pada PT Mandiri Tunas Finace Pontianak
}

\author{
Nanda Diaz Arizona*, Yulia, Adiansyah \\ Fakultas Teknik dan Informatika, Sistem Informasi Akuntansi, Universitas Bina Sarana Informatika, Pontianak, Indonesia \\ Email: 1," nanda.ndz@bsi.ac.id, ${ }^{2}$ yulia.yla@bsi.ac.id \\ Email Penulis Korespondensi: nanda.ndz@bsi.ac.id \\ Submitted: 19/12/2021; Accepted: 27/12/2021; Published: 31/12/2021
}

\begin{abstract}
Abstrak-PT. Mandiri Tunas Finance adalah salah satu perusahaan showroom unit mobil yang melayani penjualan mobil secara kredit, yang terletak di Jl. Ayani Komplek Megamall Blok B. No. 35 36.PT. Mandiri Tunas Finance ini merupakan perusahaan sebagai perantara atau layanan yang membantu atau berkerja sama dengan rekanan dalam proses kredit mobil. Rekanan adalah sebuah persero terbatas yang menjual unit mobil secara kredit, namun jika calon pembeli ingin kredit mobil maka rekanan akan memperoleh data pengajuan kredit calon nasabah kemudian akan diproses melalui Mandiri Tunas Finance. Maka dari itu, masih banyak rekanan yang membutuhkan tempat menyebarkan informasi unit mobil dengan metode kredit agar diketahui secara luas oleh eksternal serta mempermudah didalam proses pembiayaan kredit mobil . Maka penulis membuat sebuah aplikasi pembiyaan kredit mobil berbasis website pada PT. Mandiri Tunas Finance yang menggunakan bahasa pemrograman PHP (Hypertext Proccesesor), dimana aplikasi ini dibuat untuk Calon nasabah dapat mengakses web tersebut untuk mengajukan kredit mobil dengan mudah dan hannya memilih unit mobil yang di inginkan di website.
\end{abstract}

Kata Kunci: Rancang Bangun; Pembiayaan Kredit Mobil; Kredit Mobil Berbasis Website; Pembiayaan; Sistem Informasi

Abstract-PT. Mandiri Tunas Finance is a car showroom company that serves car sales on credit, which is located on Jl. Ayani Megamall Complex Block B. No. 35 36.PT. Mandiri Tunas Finance is a company as an intermediary or service that helps or cooperates with partners in the car loan process. The partner is a limited liability company that sells car units on credit, but if the prospective buyer wants a car loan, the partner will obtain data on the prospective customer's credit application which will then be processed through Mandiri Tunas Finance. Therefore, there are still many partners who need a place to disseminate information on car units with the credit method so that they are widely known by external parties and make it easier for the car loan financing process. So the author makes a website-based car loan financing application at PT. Mandiri Tunas Finance uses the PHP (Hypertext Processor) programming language, where this application is made for prospective customers to be able to access the website to apply for a car loan easily and simply select the desired car unit on the website.

Keywords: Design; Car Loan Financing; Website Based Car Loans; Financing; Information Systems;

\section{PENDAHULUAN}

Pemanfaatan teknologi dapat dipergunakan untuk proses bisnis seperti hal pada perusahaan yang bergerak dibidang penjualan mobil, ada yang mengajukan kredit mobil hanya dengan mengisi data diri di website [1], teknologi dapat mendukung proses bisnis pada saat ini menjadikan informasi sebagai hal yang penting peranannya dalam menunjang jalannya operasi-operasi demi tercapainya tujuan yang diinginkan oleh perusahaan [2][3]. Penerapan teknologi website seperti penerapan layanan kepada masyarakat luar [4] [5]. Teknologi internet sudah menjadikan salah satu media informasi yang tepat, cepat dan hemat dalam penyebaran informasi yang dapat diakses oleh siapa saja dan dimana saja [6].

Penerapan teknologi komputer pada proses pengelolaan data transaksi dapat lebih cepat karena data tersimpan diperangkat keras dan diproses oleh perangkat lunak [7]. Penggunaan teknologi terkomputer dapat berupa penerapan pengelolaan data transaksi pendapatan berbasis website, penggunaan sistem terkomputerisasi para pelaku usaha dapat mengelola transaksi dan menghasilkan informasi yang diperlukan dengan waktu yang singkat [8].

PT. Mandiri Tunas Finance adalah salah satu perusahaan showroom unit mobil yang melayani penjualan mobil secara kredit, yang terletak di Jl. Ayani Komplek Megamall Blok B. No. 35 36.PT. Mandiri Tunas Finance ini merupakan perusahaan sebagai perantara atau layanan yang membantu atau berkerja sama dengan rekanan dalam proses kredit mobil. Saat ini permohonan pengajuan hannya dapat dilakukan langsung ke kantor MTF, selain itu rekanan juga masih terbatas didalam mempromosikan produk yang akan di tawarkan. Permasalahan yang ditemukan adalah pengajuan kredit mobil yang masih manual serta proses pengolahan data konsumen yang masih dilakukan pencarian data nasabah di komputer apabila dihambat masalah jaringan LAN (Local Area Network) yang terkadang disconnect. Dan proses menghitung total uang pembiayaan masih menggunakan cara konvensional yaitu dengan menggunakan kalkulator [9], sehingga dalam proses perhitungan dapat terjadi kesalahan dan membutuhkan waktu untuk melakukan perhitungan total biaya kredit karena pihak finance harus menghitung dan menulis rincian pembiayaan kredit di kertas untuk diberikan kepada calon konsumen [10]. Maka dari itu diperlukan sistem informasi pembiayaan kredit berbasis web [10] agar memudahkan pihak Mandiri Tunas Finance yang diperoleh menjadi lebih baik dengan menerapkan sistem pengelolaan kredit dan membantu rekanan untuk penyediaan informasi kredit unit mobil di website [6].

Penulis membuat sebuah aplikasi pembiyaan kredit mobil berbasis website pada PT. Mandiri Tunas Finance yang menggunakan bahasa pemrograman PHP (Hypertext Proccesesor) [11], dimana aplikasi ini dibuat untuk Calon nasabah dapat mengakses web tersebut untuk mengajukan kredit mobil dengan mudah dan tinggal memilih unit mobil 
yang di inginkan di website tersebut [6], dan hanya memberitahukan kepada rekanan dengan mengirimkan bukti pengajuan nya yang didapat dari history pengajuan di website tersebut dan tinggal klik chat yang sudah dilinkan ke Whatsaap rekanan.

\section{METODOLOGI PENELITIAN}

\subsection{Metode Pengumpulan Data}

Berikut ini adalah beberapa metode yang dilakukan oleh penulis yang digunakan didalam proses rancang bangun sistem informasi pembiayaan :

1. Metode Observasi

Penulis melalukan kunjungan langsung serta melakukan obsevasi pada PT. Mandiri Tunas Finance di Jl. Ayani Komplek Megamall Blok B. No. 35 36yang berkaitan dnegan pembiayaan kredit. Pengamatan dilakukan selama bulan September 2020. Hasil pengamatan memberikan informasi tentang permasalahan yang terjadi.

2. Metode Wawancara

Melakukan wawancara dengan staff-staff yang di sana dan juga dengan Bapak Gun Gun Wilda Selaku Manager PT. Mandiri Tunas Finance agar tambah yakin data dan permasalahan yang didapat dari observasi.

3. Studi Pustaka

Penulis melakukan pengumpulan data dengan mencari, membaca dan mengumpulkan berbagai macam buku referensi, jurnal dan literatur lainnya yang berhubungan dengan penelitian dan penulisan.

\subsection{Metode Pengembangan Sistem}

Metode pengembangan perangkat lunak bertujuan untuk mengembangkan sistem dan memberikan panduan untuk menyukseskan proyek pengembangan sistem melalui tahapan-tahapan tertentu [12]. Dalam pengembangannya metode waterfall memiliki beberapa tahapan yang runtut: (system design), Analisa Kebutuhan, Desain, Pengkodean, Pengujian [13] [14]. Adapun tahapan-tahapan dari model waterfall pada penelitian ini, diuraikan sebagai berikut:

1. Analisis Kebutuhan

Pada tahapan ini analisi kebutuhan, penulis dengan menanyakan danmendapatkan dokumen-dokumen manual apa apa saja yang harus dibutuhkan sistem sebelum penulis merancang sebuah sistem, pertama adalah kebutuhan fungsional agar sesuai kebutuhan perusahaan PT. Mandiri Tunas Finance.

2. Desain

Pada tahapan desain ini menggunakan Entity Relationship Diagram (ERD) dan Logical Record Structure (LRS) digunakan untuk pemodelan rancangan basis data, dan pemodelan diagam Unified Model Language (UML) yang terdiri dari beberapa diagram, yaitu usecase diagam, activity diagam, sequence diagram, class diagram dan deployment diagram [14].

3. Pengkodean

Dalam tahapan ini, dilanjutkan melakukan pengkodingan yang menggunakan bahasa pemrograman hypertext preprocessor (PHP) atau framework Codeigniter dan menggunakan Sublime Textsebagai texteditor dan menggunakan XAMPP yang berisikan apache, MySQL, PhpMyAdmin yang biasa untuk menjalankan website serta membuat database secara localhost serta [11].

4. Pengujian

Tahapan penguji dilakukan pengecekan pada form apa valid atau invalid contoh nya pada testing form login jika sesuai harapan maka siap diterapkan pada PT. Mandiri Tunas Finance pengujian ini dinamakan dengan black box testing[15].

\section{HASIL DAN PEMBAHASAN}

\subsection{Proses Bisnis Sistem}

Proses bisnis dijelaskan secara berurutan sebelum akan digambar pada activity diagram berjalannya pada perusahaan Mandiri Tunas Finance.

1. Proses pendaftaran data rekanan dan unit mobil perusahaannya pada MTF

Mandiri tunas finance telah membuka sebagai perantara atau menjalin kerja sama bagi rekanan penjualan unit mobil dalam memberikan proses kredit bagi calon pembeli, Pertama yang harus dilakukan oleh rekanan adalah datang ke kantor MTF, dan menanyakan persyaratan apa saja sebagai rekanan MTF, dan Pihak Finance pun menjelaskan persyaratan menjadi rekanan MTF, jika rekanan sudah mengetahui dan maka rekanan akan melakukan persetujuan dan membuat rangkuman data diri dan data-data mobil yang dijadikan file excel dan word dan file tersebut akan diberikan data-data perusahaanya (disini setiap perusahaan memiliki perusahaan tersendiri misalnya Toyota, daihatzu dll, karena MTF ini sebagai perantara untuk meyakinkan calon kredit mobil agar terjamin) jika sudah maka finance siap menerima data yang dibuat oleh rekanan dan memasukan data mobil ke M.Excel. setelah itu,finance pun membuat sebuah iklan atau brosur menggunakan Photoshop cs6 dan jika sudah 
dibuatkan makan diberikan kepada rekanan apabila dibutuhkan, kemudian marketing dari perusahaan nya akan menawarkan kredit di kerumunan masyarakat.

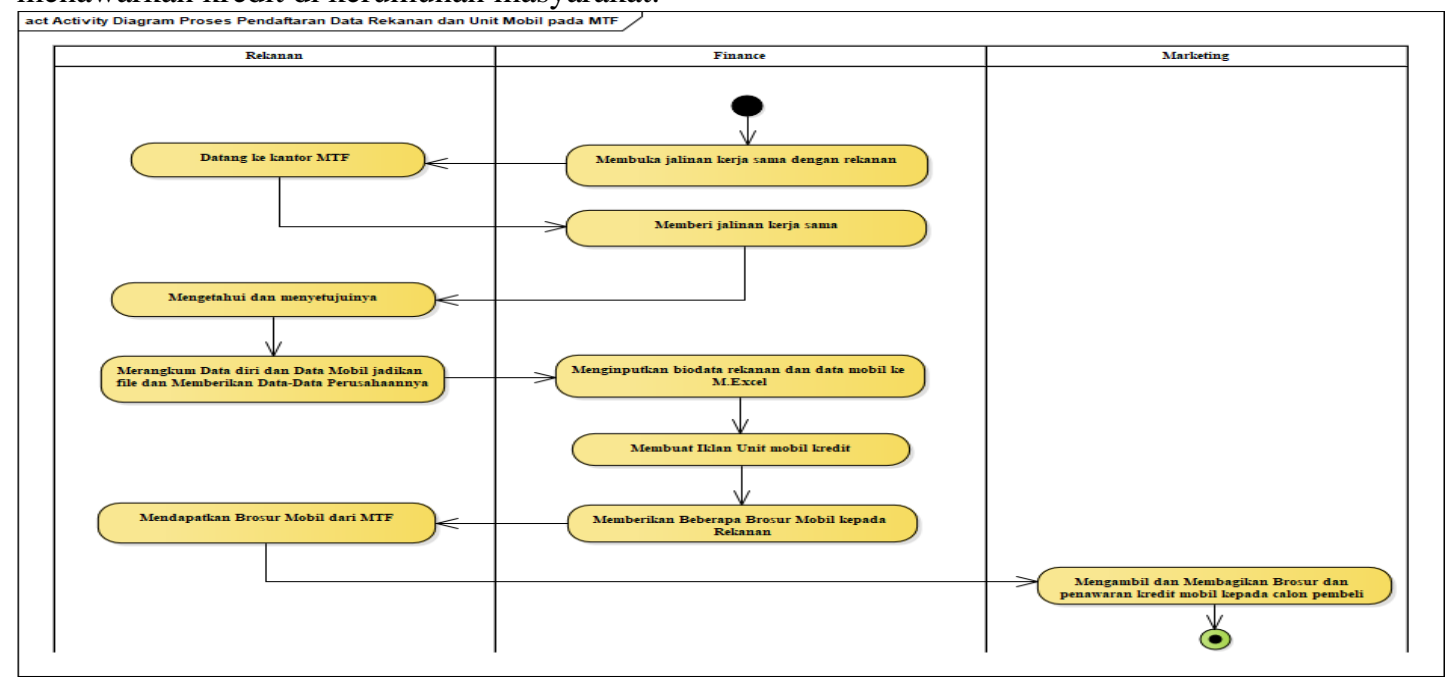

Gambar 1. Activity Diagram Proses Pendaftaran Dara Diri Sebagai Rekanan dan data mobil pada MTF

2. Proses Bisnis Marketing Penawaran Kredit Mobil

Marketing menawarkan kredit Mobil kepada masyarakat dengan cara membagikan brosur unit mobil kepada calon pembeli dengan syarat proses kredit, apabila si calon debitur atau nasabah berminat untuk kredit maka marketing akan mendaftarkan calon kredit menjadi calon nasabah jika tidak maka marketing tetap mencari calon nasabah lainnya. Jika sudah terdaftar maka calon nasabah menyetujui dan datang ke kantor Mandiri Tunas Finance untuk mengisi data lainnya dan melanjuti proses kredit, maka nasabah akan dilayani oleh finance. Jika sudah diisi maka marketing merangkum formulir pengajuan kredit mobil dan diproses lanjut (survey).

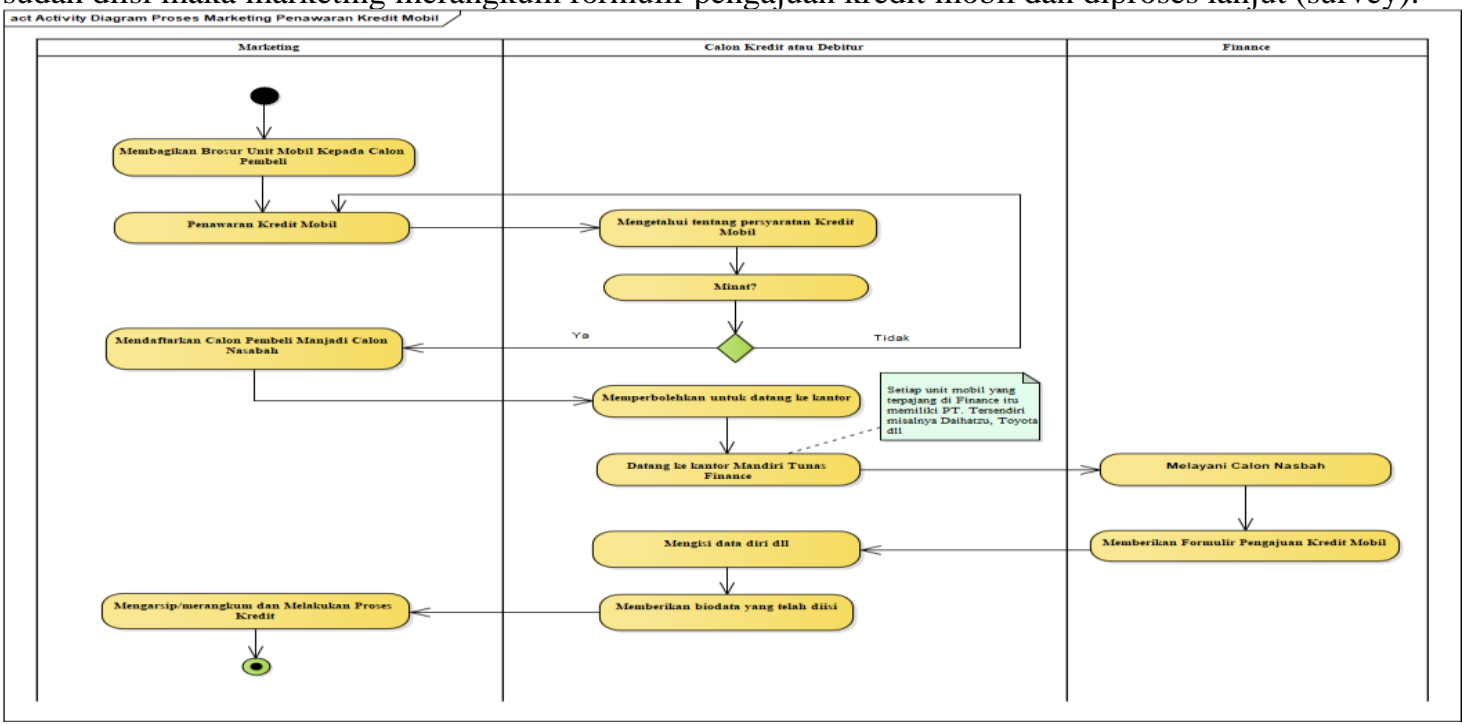

Gambar 2. Activity Diagram Proses Marketing Menawarkan Kredit Mobil

3. Proses Bisnis Proses Kredit dan Pembayaran Kwitansi hingga Penyerahan BPKB

Marketing mengunjungi ke tempat calon nasabah dan meminta centang persyaratan seperti KTP, KK, Akta dll. Jika sudah maka calon nasabah menyetujui persyaratannya dengan tanda tangan pada formulir yang telah diisi sebelumnnya. Marketing pun juga mendatangani persyaratan yang telah dicentang dan akan dokumen tersebut akan diberikan kepada MTF atau Finance, Finance pun siap menanggapi dan memverifikasi pengajuan kredit mobil, jika datanya kurang maka pengajuan nya ditolak jika sudah lengkap maka pengajunnya disetujui, dan diproses lanjut dengan meminta calon nasabah untuk datang ke kantor MTF dan membawah persyaratan yang sudah dicentang, jika sudah calon nasabah pun diwawancarai dan finance meminta persyaratan yang telah di centang seperti (KTP, KK, dll) untuk di foto copy, setelah sudah lengkap maka diproses ke Kasir, dan calon nasabah diminta oleh finance untuk membayar uang muka 1 kali pada kasir (pembayaran kwitansi ini dibayar tiap bulan tergantung jangkah waktu yang dipinjam)jika sudah maka kasir membuat berita acara serah terima, membuat surat persyaratan penyerahan BPKB, hingga penyerahan unit mobil kepada MTF yang di bekali formulir faktur kendaraan dan BPKB. 


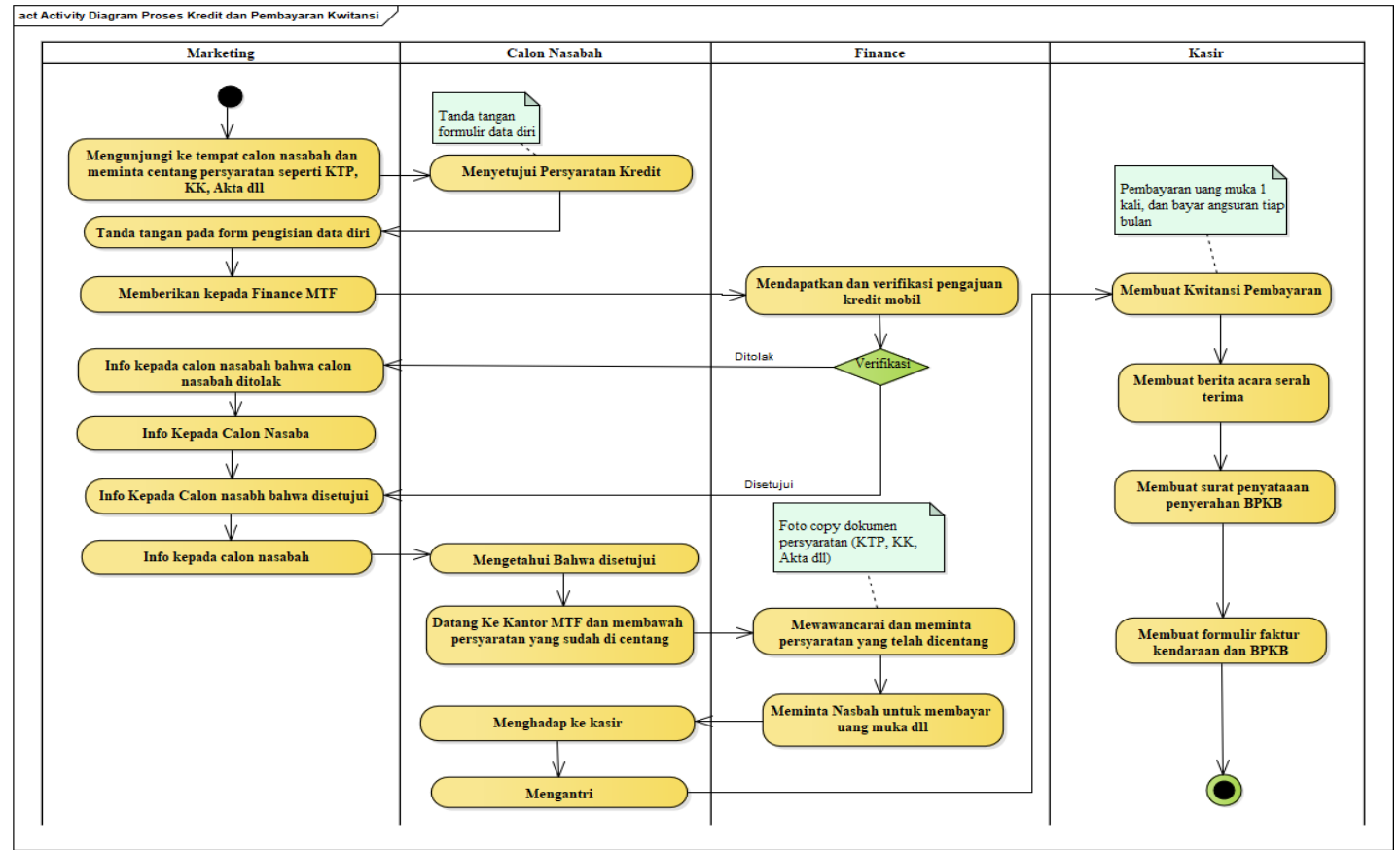

Gambar 3. Activity Diagram roses Kredit dan Pembayaran Kwitansi hingga Penyerahan BPKB

\subsection{Tahapan Analisis}

Tahapan analisis akan menjelaskan tentang analisis kebutuhan sistem. Berikut adalah spesifikasi kebutuhan (System Requirement) dari Aplikasi .

1. Kebutuhan Akses Calon Nasabah
a. Daftar
b. Login
c. Menambah Unit Mobil ke Transaksi Kredit
d. Mencari Unit Mobil lainnya
e. Dapat klik Chat yang langsung diarahkan ke whatsaap rekanan
f. Mengisi Biodata Calon Nasabah
g. Melihat Info Pengajuan
h. Melihat Info Pembayaran
i. Melihat Laporan Jurnal

2. Kebutuhan Akses Kasir

a. Login

b. Mengelola Pembayaran

c. Mengelola Acara Serah-Terima

d. Mengelola Surat Pernyataan Penyerahan BPKB

e. Mengelola Formulir Faktur Kendaraan dan BPKB

3. Kebutuhan Finance
a. Login
b. Mengelola Data Mobil
c. Mengelola Pengajuan
d. Mengelola Jurnal
e. Mengelola Akun Nasabah

4. Kebutuhan Akses Branch Manager
a. Login
b. Mengelola Admin
c. Melihat Laporan Pembayaran
d. Melihat Laporan Jurnal

\subsection{Use Case Diagram}

Agar system dapat dijelaskan lebih jelas maka digambarkan sebuah use case untuk pemodelan system yang telah dibuat [7]. 


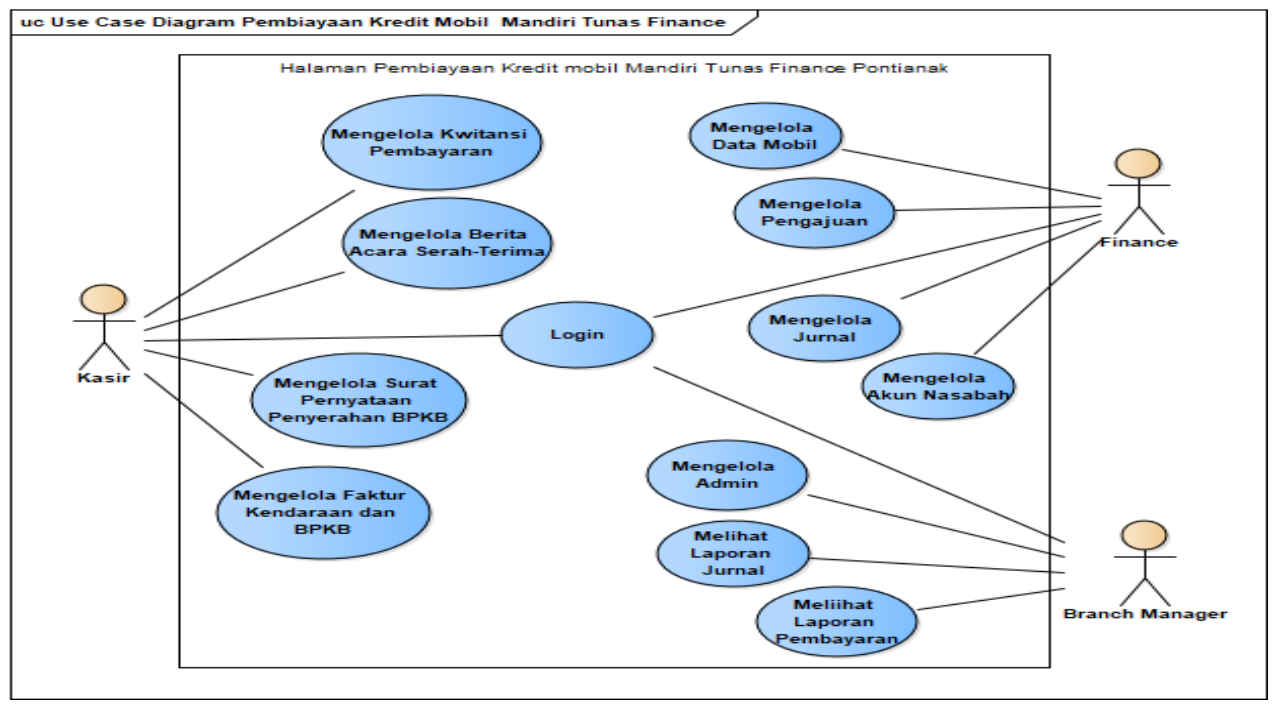

Gambar 4. Use Case Diagram Pembiayaan Kredit Mobil Pada PT.Mandiri Tunas Finance

Usecase diagram diatas tersebut memiliki tiga aktor bernama Kasir, dan actor satunya adalah actor Finance, dan actor satunya adalah branch manager, ini memiliki atribut pertama Kasir memiliki caseMengelola Kwitansi Pembayaran, Mengelola Berita Acara Serah-Terima, Login, Mengelola Surat Pernyataan Penyerahan BPKB, Mengelola Faktur Kendaraan dan BPKB, sedangkan Finance memiliki case Mengelola Data mobil, Mengelola Pengajuan, Mengelola Jurnal, Mengelola Akun Nasabah, sedangkan Branch Manager memiliki case mengelola Admin, Melihat Laporan Jurnal, Melihat Laporan Pembayaran.

\subsection{Desain Basis Data}

Desain pada penelitian ini akan memberikan penjelasan desain dengan memberikan penjelasan tentang ERD, LRS, Software Architecture, user interface dan spesifikasi hardware serta software.

\subsubsection{Entity Relationship Diagram (ERD)}

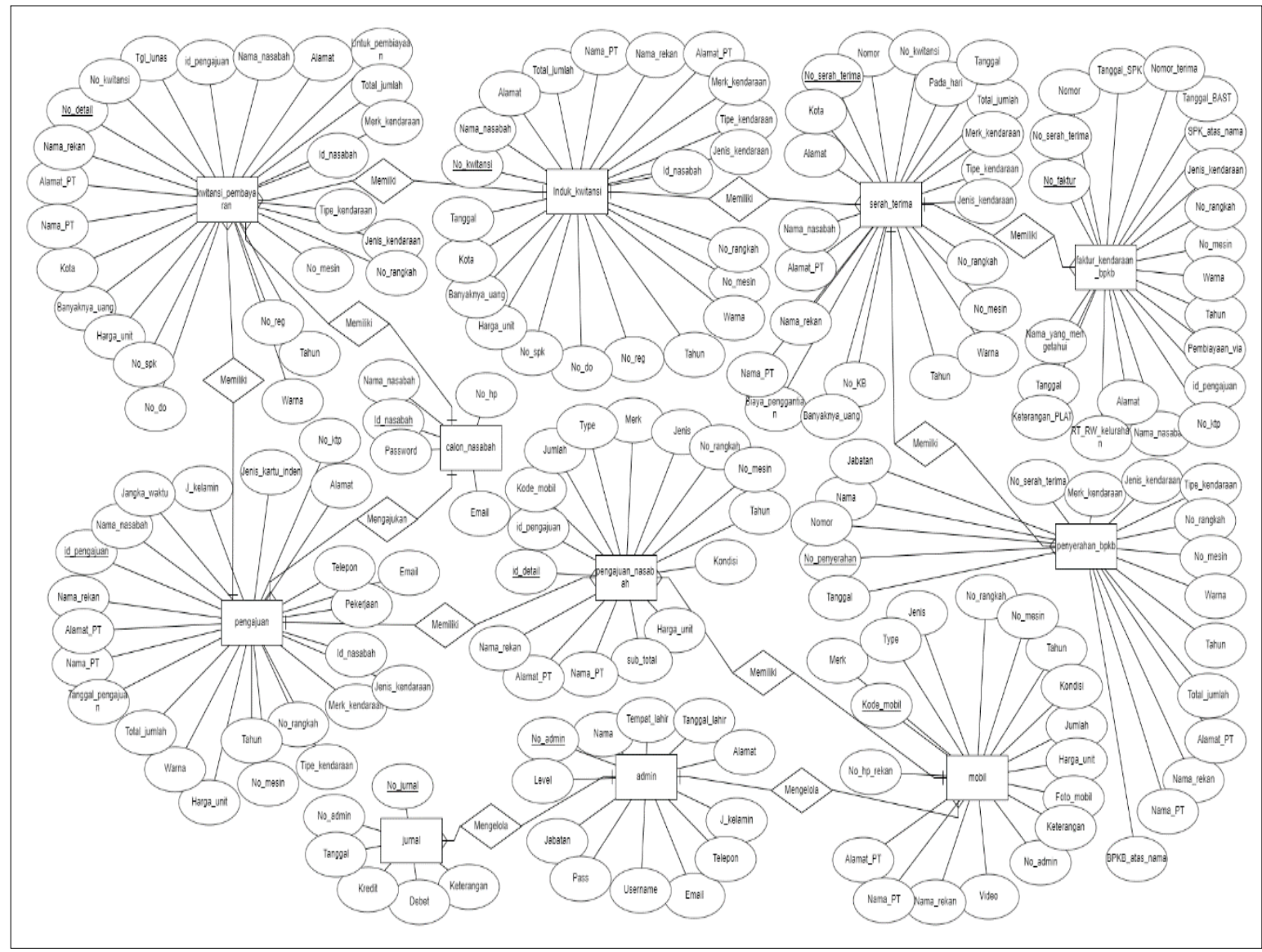

Gambar 5. Entity Relationship Diagram (ERD) 
Entity Relationship Diagram pada gambar 5 memiliki entity sebanyak 11 (sebelas) yang dimulai dari entity admin, jurnal, calon nasabah, mobil, pengajuan_nasabah, pengajuan, induk_kwitansi, kwitansi_pembayaran, serah_terima, faktur_kendaraan_bpkb, penyerahan_bpkb.

\subsubsection{Logical Record Structure (LRS)}

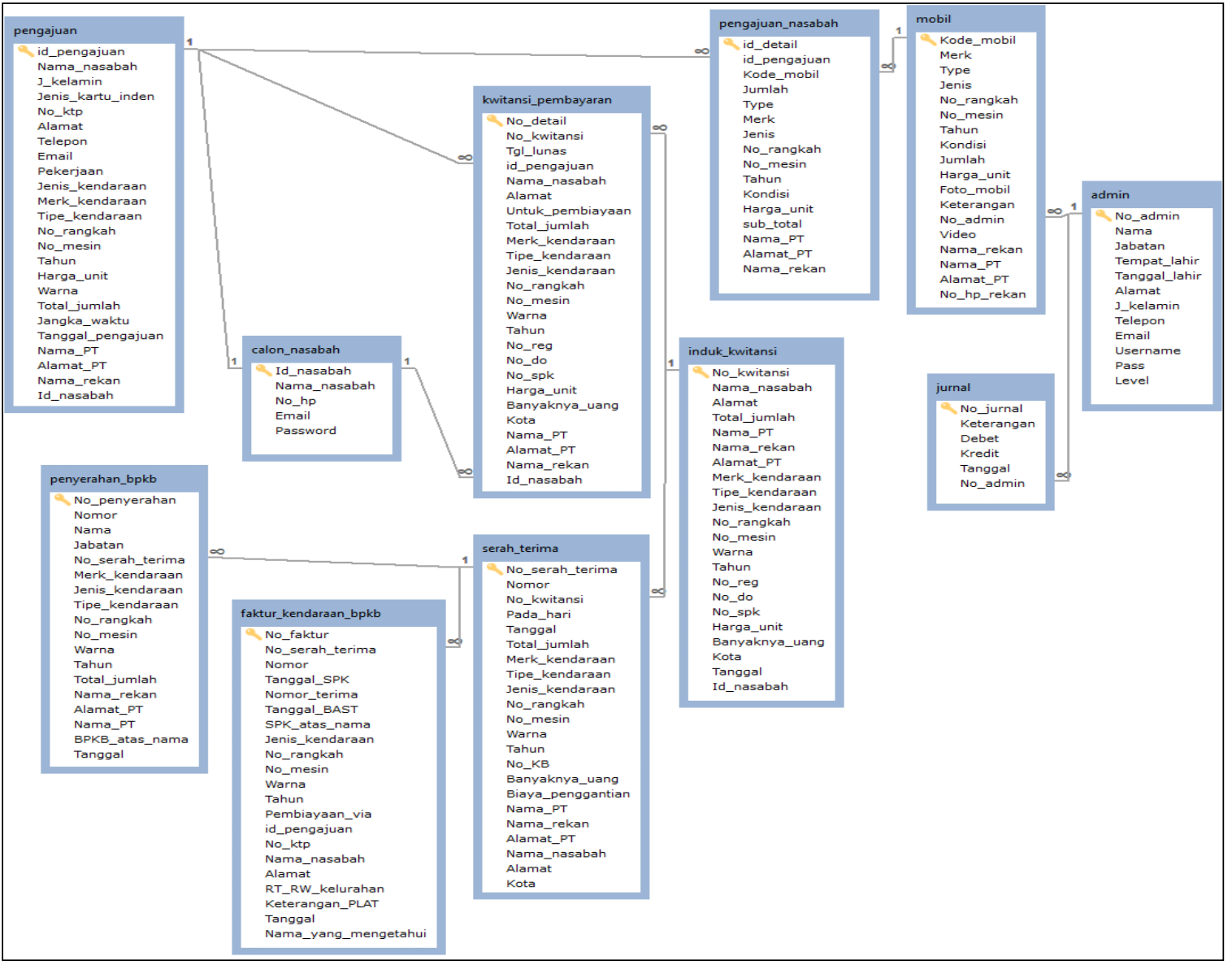

Gambar 6. Logical Record Structure (LRS)

Logical Record Structure (LRS) pada gambar 6 memiliki entity sebanyak 11 (sebelas) yang dimulai dari Table admin, jurnal, calon nasabah, mobil, pengajuan_nasabah, pengajuan, induk_kwitansi, kwitansi_pembayaran, serah_terima, faktur_kendaraan_bpkb, penyerahan_bpkb.

\subsubsection{Sequence Diagram}

A. Sequence Diagram Calon Nassabah

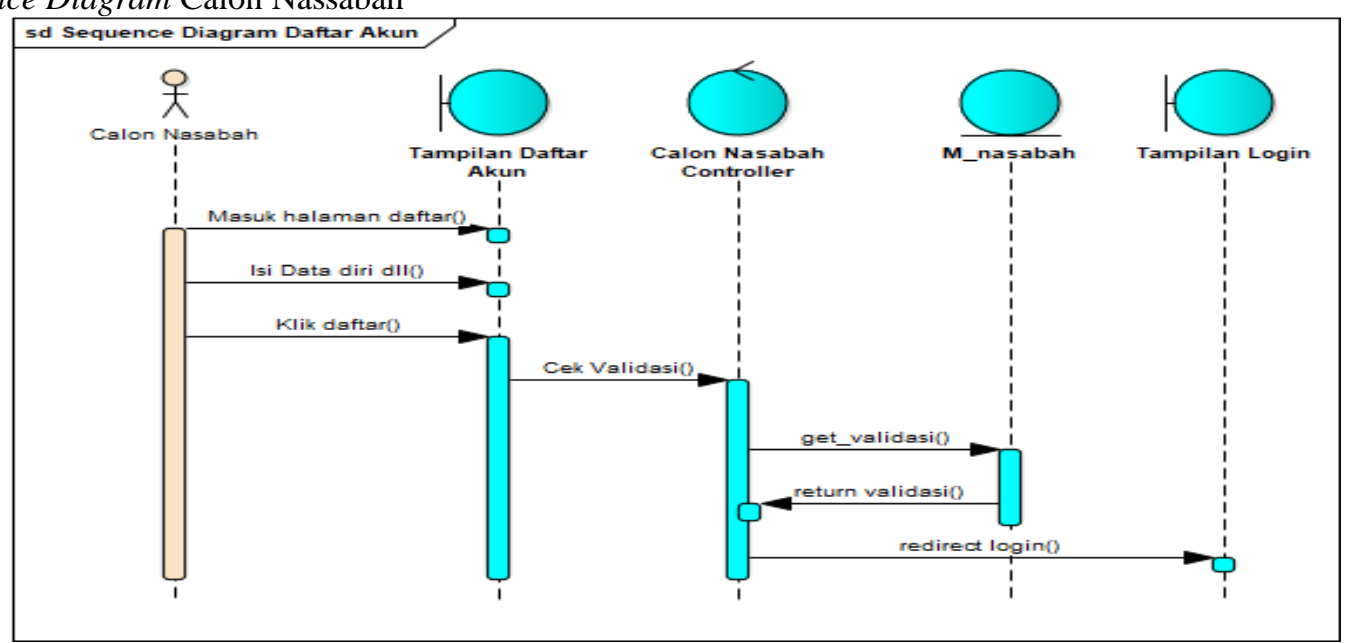

Gambar 7. Sequence Diagram Daftar Akun

Sequence Diagram Calon Nasabah pengguna baru dapat mendaftarkan akun baru. 
Building of Informatics, Technology and Science (BITS)

Volume 3, No 3, December 2021, Page 285-294

ISSN 2684-8910 (media cetak)

ISSN 2685-3310 (media online)

DOI 10.47065/bits.v3i3.1069

B. Sequence Diagram Calon Nasabah Mengajukan Kredit

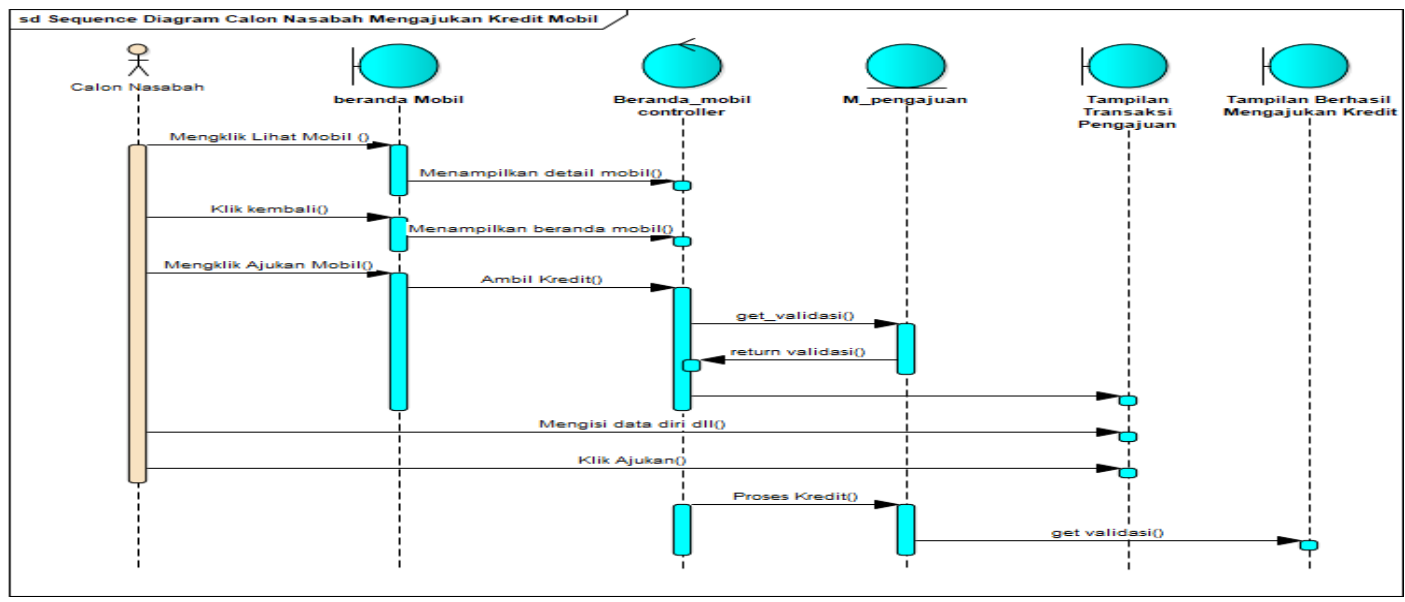

Gambar 8. Sequence Diagram Calon Nasabah Mengajukan Kredit

C. Sequence Diagram Calon Nasabah Melihat Info Pengajuan

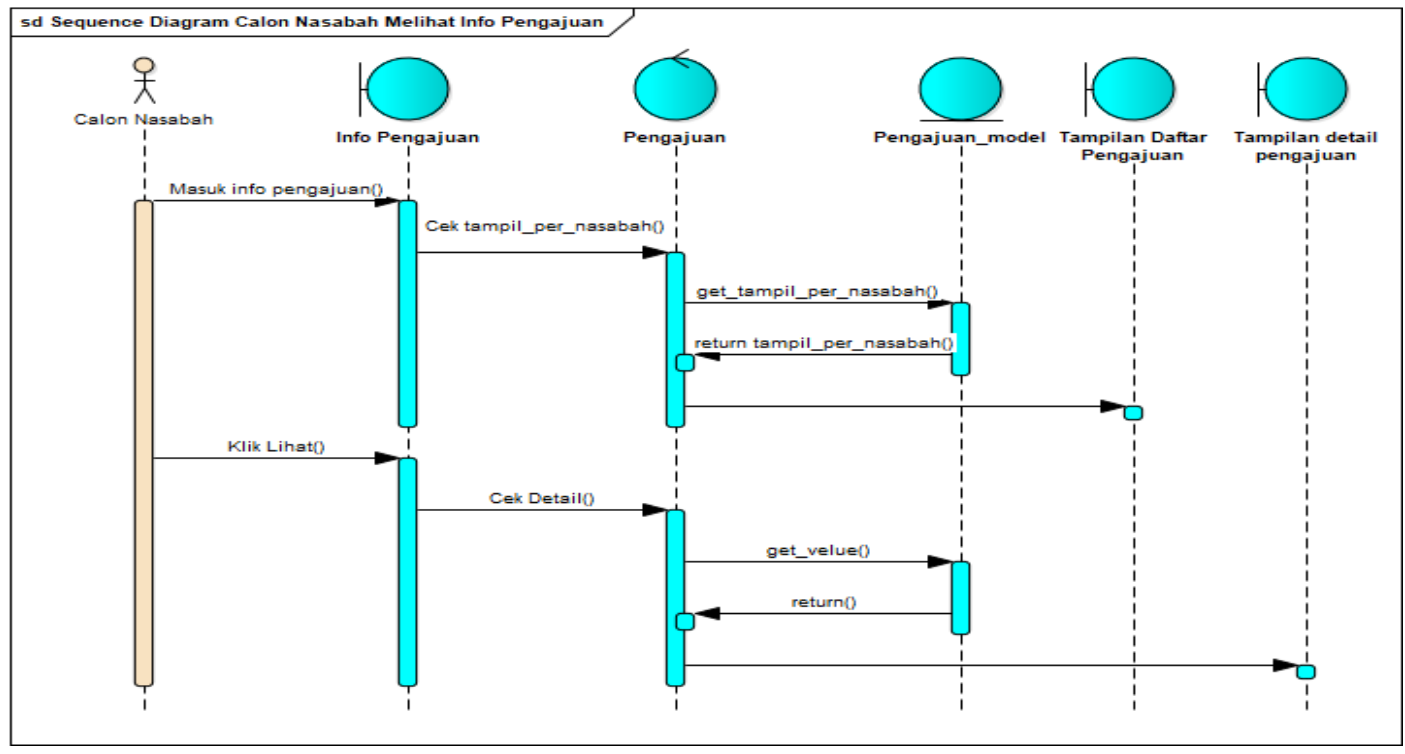

Gambar 9. Sequence Diagram Calon Nasabah Mengajukan Kredit

2. Deployment Diagram

Deployment diagram digunakan untuk memvisualisasikan hubungan antara perangkat lunak dan Perangkat keras. Secara spesifik deployment diagram dapat membuat physical model tentang bagaimana komponen perangkat lunak digunakan pada komponen perangkat keras. Berikut rancangan deployment diagram pada sistem yang dibangun

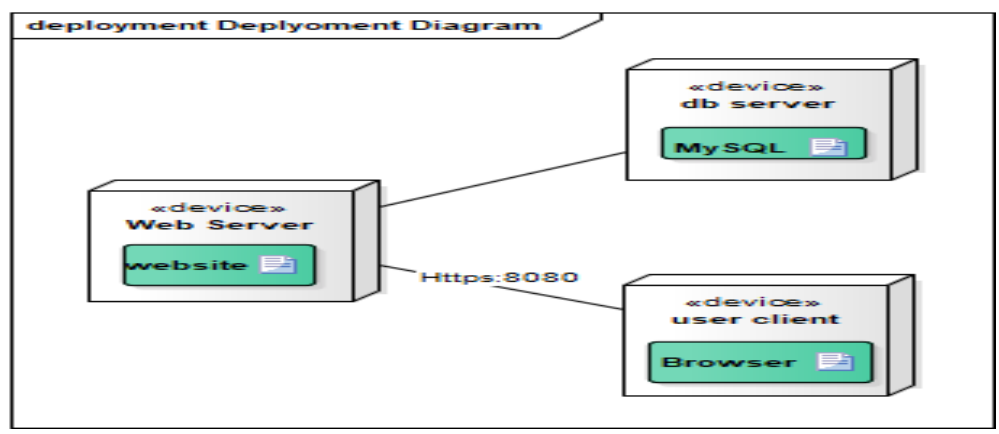

Gambar 10. Deployment Diagram

Pembuatan sistem pendapatan penjualan divisualisasikan dengan deployment diagram dan dapat menjelaskan tentang komponen yang terkait berhubungan dengan database, server dan sistem informasi yang dibangun. 


\subsection{Desain User Interface}

1. Halaman Beranda Konsumen

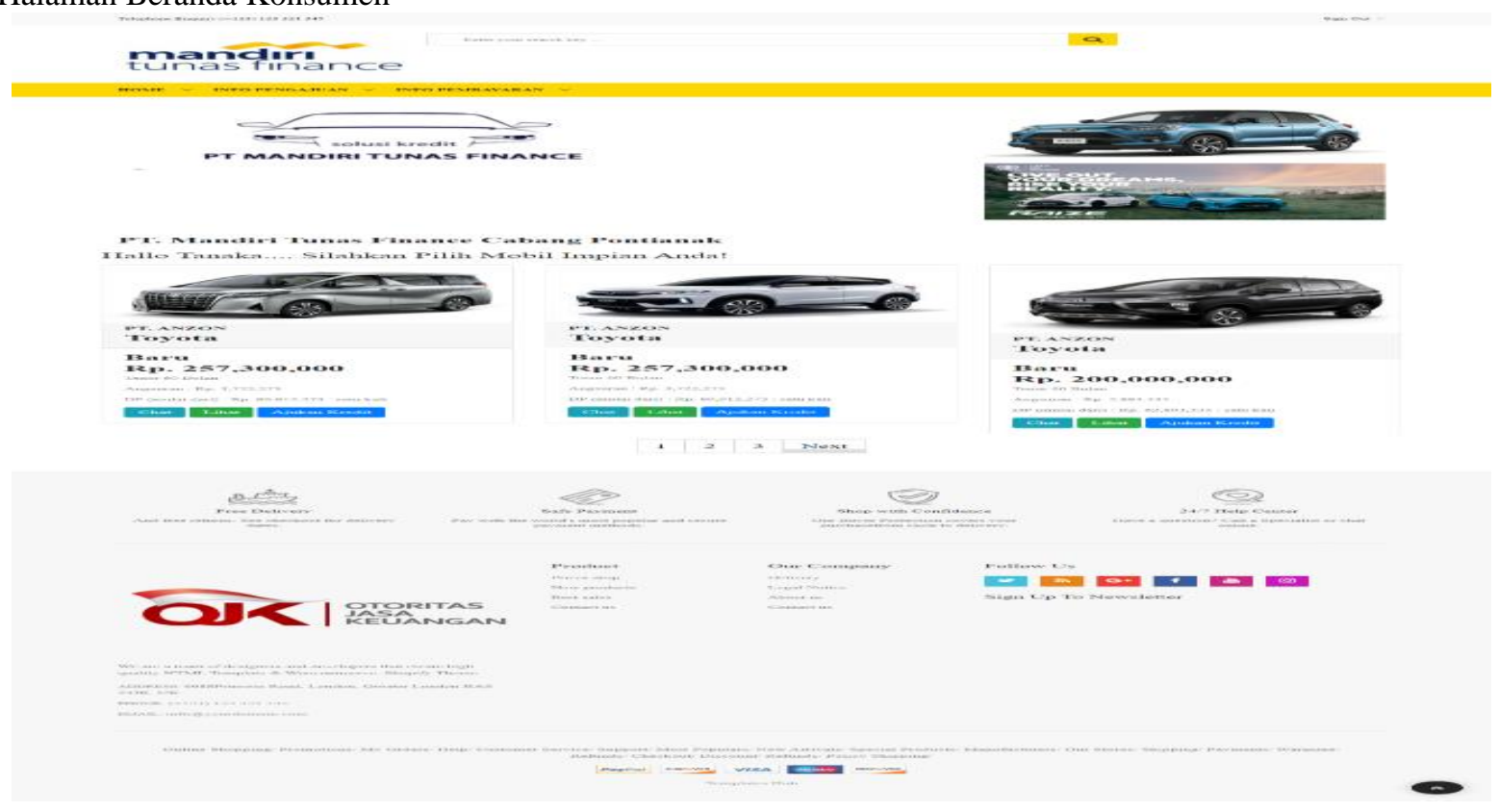

Gambar 11. Halaman Beranda Konsumen

Pada halaman beranda, konsumen maupun calon konsumen dapat melihat informasi tentang kendaraan yang akan dipilih untuk melakukan pembiayaan kredit.

2. Halaman Login

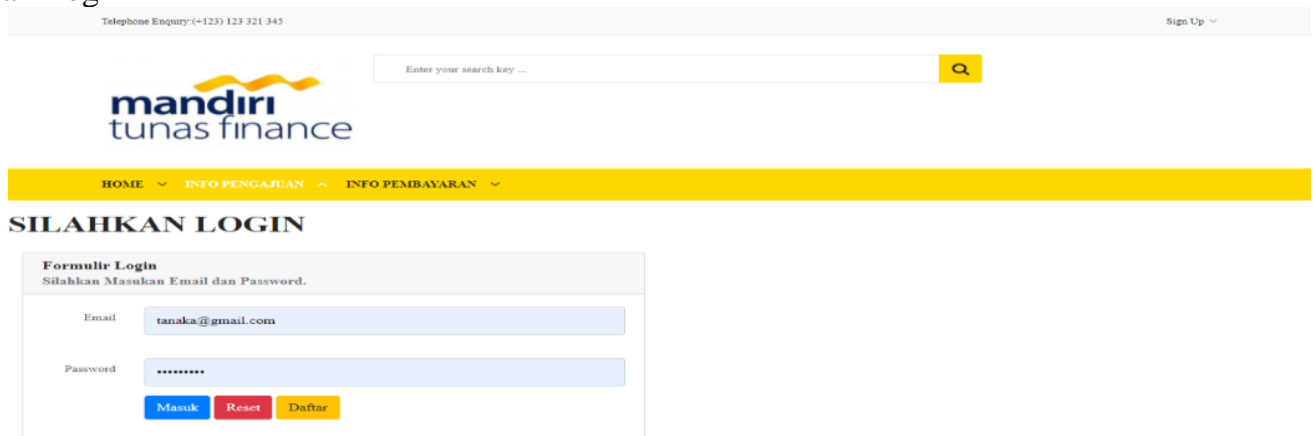

Gambar 12. Halaman Login

Pada halaman login konsmen dapat login terlebih dahulu untuk melakukan pengajuan kredit mobil dan melihat info pengajuan, serta melihat info pembayaran. Namun jika belum punya akun maka konsumen harus klik tombol daftar maka sistem akan menampilakn form daftar akun.

3. Halaman Daftar Akun

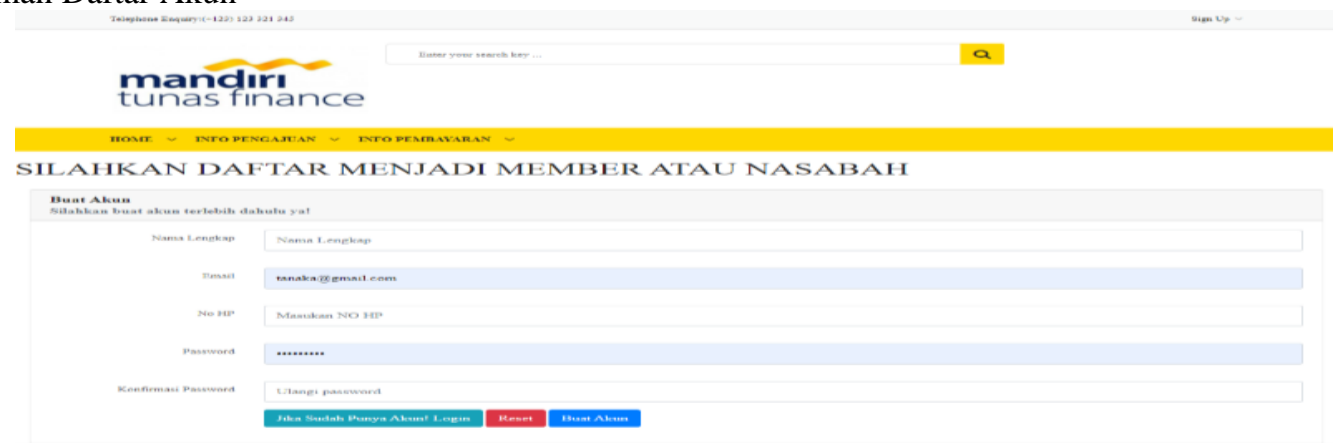

Gambar 13. Halaman Calon Nasabah Daftar Akun

Pada Halaman daftar akun, disini calon konsumen diharapkan untuk mendaftarkan akun terlebih dahulu, dengan mengisi nama lengkap, email, no hp, password, Konfirmasi_password. 
4. Halaman Detail Kendaraan

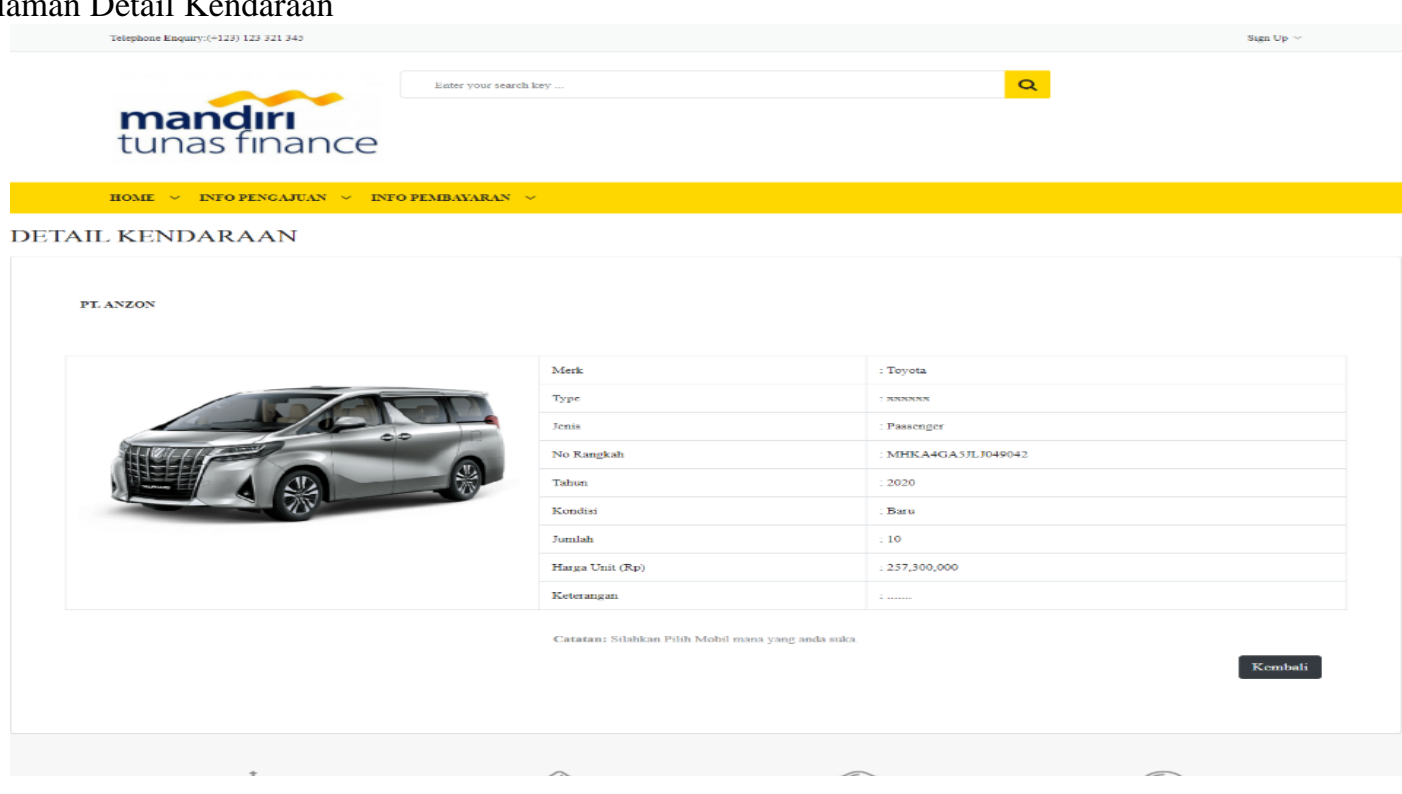

Gambar 14. Halaman Detail Kendaraan

Pada halaman detail kendaraan, disini calon konsumen dapat melihat detail kendaraan dan mengharuskan login ke system dan konsumen dapat langsung klik ajukan kredit.

5. Halaman Pengajuan Kredit

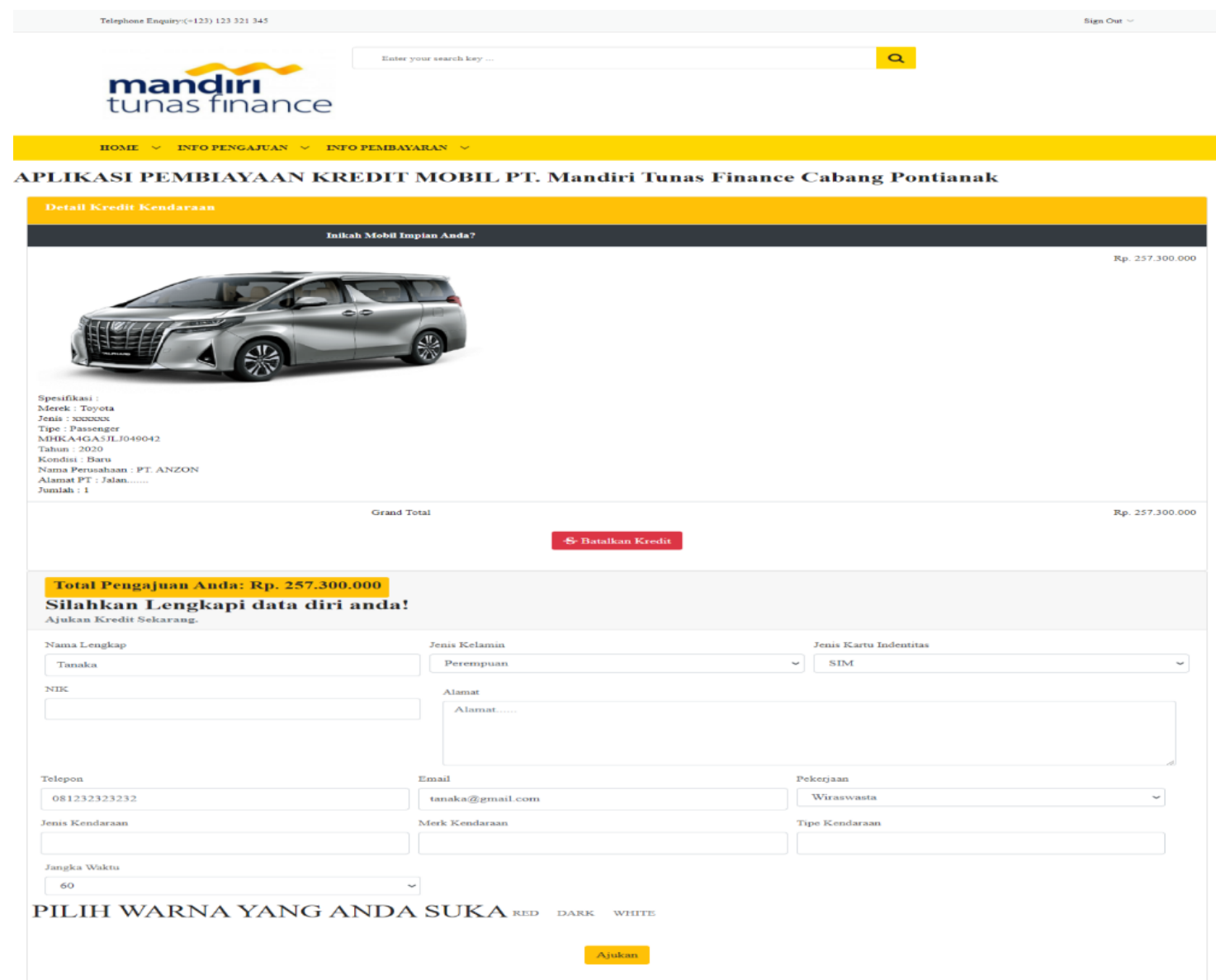

Gambar 15. Halaman Pengajuan Kredit

Pada halaman pengajuan kredit, disini konsumen telah klik tombol ajukan maka sistem akan menampilkan form isi data diri seperti diatas yang berisi kolom nama lengkap, jenis kelamin, jenis kartu indentitas, NIK, Alamat, Telepon, Email, pekerjaan, jenis kendaraan, merek kendaraan, dan tipe kendaraan. 


\section{mandırı}

tunas finance

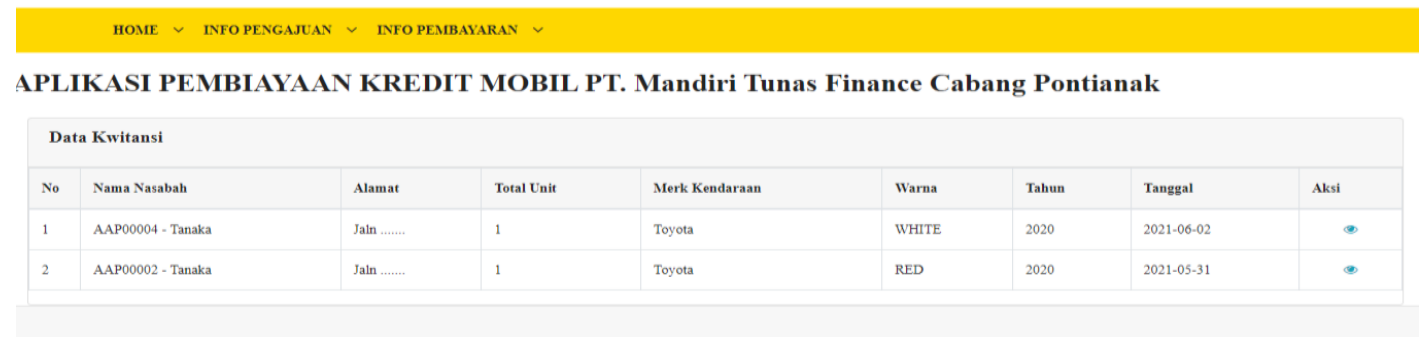

Gambar 16. Halaman Pembayaran Kwitansi

Pada halaman pembayaran kwitansi konsumen dapat melihat info pembayaran, melihat detail pembayarannya

\section{KESIMPULAN}

Pembuatan Aplikasi Pembiayaan Kredit Mobil memudakan rekanan dalam penyebaran informasi kredit mobil. Aplikasi pembiayaan Kredit Mobil ini telah memberikan informasi pengajuan kredit yang akurat serta bagi calon konsumen sehingga tidak harus meminta formulir ke kantor karena dapat mengajukan pembiayaan kredit mobil via website. Dengan adanya aplikasi pembiayaan kredit mobil membantu untuk menghitung total biaya kredit, karena sudah ada sistem otomatis didalam tampilan detail pengajuan kredit unit mobil.

\section{REFERENCES}

[1] A. B. Swasono and Y. Kusnadi, "Implementasi Sistem Informasi Angsuran Kredit Mobil (Studi Kasus Pt Asrindo Jaya Jakarta)," J. Techno Nusa Mandiri, vol. 14, no. 1, pp. 71-76, 2017, [Online]. Available: http://ejournal.nusamandiri.ac.id/ejurnal/index.php/techno/article/view/403/310.

[2] J. \& R. F. Strauss, E-Marketing, 5th ed. New Jersey: Upper Saddle, 2009.

[3] C. ND Arizona, Yulia, “Analisis Perbandingan Efektivitas Penggunaan Media Komunikasi Berbasis Messenger," Ecodemica, vol. 3, no. 1, pp. 54-65, 2019, doi: https://doi.org/10.31294/jeco.v3i1.4446.

[4] M. Danuri, "Development and Transformation of Digital Technology," Infokam, vol. XV, no. II, pp. 116-123, 2019.

[5] A. I. Nofyat and A. Arisandy, "Sistem Informasi Pengaduan Pelanggan Air Berbasis Website Pada Pdam Kota Ternate," IJIS - Indones. J. Inf. Syst., vol. 3, no. 1, 2018, doi: 10.36549/ijis.v3i1.37.

[6] R. Adwiya, N. D. Arizona, M. R. Pambudi, U. Bina, and S. Informatika, "Sales And Purchase Of Website Based Heavy Equipment Sparepart," J. Teknol. dan Manaj. Inform., vol. 5, no. 1, 2019.

[7] N. D. A. Nasihin. Muhamad, Yulia, "Sistem Informasi AKUNTER ( Akuntansi Terpadu ) Berbasis Web Sebagai Pengelolaan Transaksi Keuangan Pada Mutiara Laundry,” vol. 6, no. 3, pp. 401-407, 2020.

[8] M. N. Yulia, ND. Arizona, "Sistem informasi penjualan produk pontimarket," J. Khatulistiwa Inform., vol. VIII, no. 1, pp. 53-59, 2020, doi: https://doi.org/10.31294/jki.v8i1.8300.g4162.

[9] W. Irmayani and R. D. Utami, "Pengelolaan Keuangan Berbasis Web PT . Mutualplus Global Resources Cabang Pontianak," vol. 01, no. 01, pp. 40-49, 2020.

[10] M. Ridani, “Aplikasi Pendataan Transaksi, Keuangan Dan Persedian Barang Pada PT. Best Stamp Indonesia Berbasis Web," 2021, [Online]. Available: http://eprints.uniska-bjm.ac.id/5384/\%0Ahttp://eprints.uniska-bjm.ac.id/5384/1/Artikel M. Ridani_16630058-dikonversi.pdf.

[11] Solichin, "Pemrograman Web dengan PHP dan MySQL - Google Books," Penerbit SPARTA, no. June, pp. 1-122, 2016, [Online]. Available: https://www.google.co.id/books/edition/Pemrograman_Web_dengan_PHP_dan_MySQL/k8GDAAAQBAJ $? \mathrm{hl}=\mathrm{id} \& \mathrm{gbpv}=1 \& \mathrm{dq}=\mathrm{php} \& \mathrm{pg}=\mathrm{PA} 12 \&$ printsec=frontcover.

[12] E. S. Arizona. Nanda Diaz, "Sistem Informasi Akuntansi Simpan Pinjam Pada Sinar Kalimantan Dengan Metode Pengembangan Waterfall," J. Sist. Inf. Akunt., vol. 2, no. 01, pp. 11-20, 2021, [Online]. Available: https://ejournal.bsi.ac.id/ejurnal/index.php/justian.

[13] T. E. P. Muhamad, "PENERAPAN METODE WATERFALL PADA SISTEM INFORMASI INVENTORI PT. PANGAN SEHAT SEJAHTERA,” J. Inkofar, vol. 1, no. 2, pp. 30-40, 2017.

[14] R. A. Mohammad Badrul, "Penerapan Metode Waterfall pada Perancangan Sistem Informasi Pendaftaran Siswa Baru," J. Sains Komput. Inform., vol. 5, no. 2, pp. 52-61, 2021, [Online]. Available: http://ejurnal.tunasbangsa.ac.id/index.php/jsakti/article/view/297/275.

[15] C. R. Wensen, H. Manossoh, F. Ekonomi, and J. Akuntansi, "PENERAPAN METODE PROCESS COSTING SYSTEM DALAM PENENTUAN HARGA POKOK PRODUKSI PADA PT . CONBLOC INDONESIA SURYA Process costing is a system of pricing of basic products used in industrial production that organizes activities for a specific product based on," pp. $1-10$ 